\title{
Factors Affecting Students' Attitudes towards E-Learning
}

DOI: 10.7595/management.fon.2017.0016

\begin{abstract}
E-learning is becoming a widespread method of gaining knowledge in a global environment. Accessibility and variety of online content encourage more and more people to get involved in learning using digital resources. However, there has been limited research exploring the factors that could influence students' attitudes regarding e-learning. In this study, field research was conducted to determine which factors affect students' attitudes towards e-learning. The questionnaire was developed to collect data about factors that influence attitudes towards e-learning. A total of 286 students were the study cohort. Three factors were identified using principal component analysis: e-learning usefulness, ease of use, and content design. Regression analysis was conducted to determine the strength of the factors influencing attitudes towards e-learning. All factors had a significant influence on attitude towards e-learning. Usefulness of e-learning had the strongest impact on students' e-learning intention. Our study will contribute to the existing work in this field by emphasizing the importance of perception of content design on attitudes towards e-learning.
\end{abstract}

Keywords: e-learning, attitudes towards e-leaning, factors, Technology Acceptance Model, e-learning content design.

JEL classification: D83, C30, 039

\section{Introduction}

E-learning is the use of information technologies to deliver information for education and training, regardless of time restrictions or geographic proximity (Isik, 2008; Shee \& Wang, 2008; Sun, Tsai, Finger, \& Chen, 2008). It is one of the most significant developments in the IT industry (Wang, 2003). In recent years, E-learning has become a popular way of gaining knowledge (Benkovic \& Dobrota, 2012) for many students worldwide, because it represents an easy, modern, and cost-effective solution for universities and lecturers, as well as students (Berman \& Levine, 2008; Bouhnik \& Marcus, 2006; Capper, 2002; Douglas, Gregg, \& Mangione, 2001; Motiwalla, 2007). E-learning systems have been widely used and applied in education in the last 20 years (Kim \& Bonk, 2006). Unlike the most developed countries, where e-learning is both common and widely used, in developing countries, such as Serbia, it is still new (Damnjanovic, Jednak, \& Mijatovic, 2015).

A number of authors have considered the benefits of e-learning (Bouhnik \& Marcus, 2006; Capper, 2002; Concannon, Flynn, \& Campbell, 2005; Horvat, Dobrota, Krsmanovic, \& Cudanov, 2015). Digital literature can contain audio or video content that provides a better sensory experience and more effective learning (Jovic, Milutinovic, Kos, \& Tomazic, 2012). The most commonly cited benefits of e-learning are that it can take place at any time and place, through asynchronous interaction and group collaboration. According to Capper (2002), the possibility of freedom in deciding the time and place of accessing digital content is one of the main benefits for modern students. 
Bearing in mind the benefits of e-learning, many authors have analyzed the factors that influence e-learning attitudes and intentions. For example, Lee (2010) has developed a combination of three models: Expectation Confirmation Model (Oliver, 1986), Technology Acceptance Model (TAM) (Davis, Bagozzi, \& Warshaw, 1989), and Theory of Planed Behavior (Netemeyer, Ryn, \& Ajzen, 1991). He has also examined the effects of satisfaction, perceived usefulness, attitude, flow theory, subjective norms, and perceived behavioral control on adoption and continuation of e-learning. The TAM shows a great potential in examining attitudes and intentions to use e-learning (Masrom \& Teknologi, 2007; Roca, Chiu, \& Jose, 2006; Yi \& Hwang, 2003). According to TAM, the perceived benefits of and attitudes to the specific technology influence users to use a particular technology (Davis et al., 1989). In addition, intention towards e-learning is the main prerequisite for its actual use.

Only a few studies have examined the influence of different factors on attitudes towards e-learning (Liaw \& Chen, 2007; Park, Nam, \& Cha, 2012). Moreover, to the best of our knowledge, only few studies dealing with the influence of different types of content included in the e-learning materials, for example, animations, video, or teacher's voice, on attitudes towards e-learning have been conducted (Buzzetto-More, 2015; Cakir \& Solak, 2014; Costley \& Lange, 2017; Hung, Yang, Fang, Hwang, \& Chen, 2014; Liaw \& Chen, 2007; Luzon \& Leton, 2015; O'Connor, McDonald, \& Ruggiero, 2014; te Pas, Waard, Blok, Pouw, \& van Dijk, 2016; Violante \& Vezzetti, 2014; Wang \& Antonenko, 2017). In this study, we applied the TAM theory and extended it with another factor with a potential impact on e-learning attitudes. We analyzed e-learning ease of use, e-learning usefulness, and the design of the e-learning system.

The ease of use reflects users' perception of the ease of adopting a system (Davis et al., 1989). If systems are easier to use, the attitudes, learning experiences, and satisfaction with e-learning are more positive (Arbaugh, 2002). Consequently, it increases the likelihood of repeated use of e-learning in the future (Arbaugh, 2002). There are numerous ways to facilitate handling e-learning systems. Usually, this can be achieved through good interface, with different ways to access a particular function of a system (Branscomb \& Thomas, 1984).

Usefulness is considered a decisive factor affecting educational effectiveness (Virvou \& Katsionis, 1995). Usefulness can be considered as a quality or an attribute that represents the ease of use of human-computer interfaces (Kneebone, 2003). The ISO 9241 defines it as "the extent to which a product can be used by specified users to achieve specified goals with effectiveness, efficiency and satisfaction in a specified context of use". Sharma, Dick, Chin, \& Land (2007) define usefulness as an essential factor to increase learners' self-regulation in e-learning environments, which can enhance their intention to use e-learning.

A large number of authors agree that interactive instructional design is an essential factor for learning satisfaction and success (Hong, K-W, \& D, 2003; Jiang \& Ting, 1998; Nahl, 1993; Schwartz, 1995). According to Te'eni (2004), some design attributes are more important to functionality and others are more relevant to system support. However, system design is a crucial aspect that affects users' continuance in the use of a system (Te'eni, 2004).

The aim of the present work was to contribute to the growing body of technology acceptance literature by examining the relationships between TAM variables and attitudes towards e-learning. Moreover, we expanded the TAM model with the design features. Specifically, we conducted a study to develop a measure that will predict students' usage of e-learning. In addition, we provided evidence of internal reliability of the developed measure.

\section{The present study}

The present study investigates which factors influence students' attitudes towards e-learning. It is grounded on the TAM theory, extended with different e-learning content elements. The initial pool of 13 items was examined using Principal Component Analysis (PCA). After examining internal reliability of the construct, we strived to examine the influence of given factors on the attitude towards e-learning. To achieve this, we conducted a multiple linear regression analysis.

\subsection{Participants}

Participants in the study were 286 students from the University of Belgrade. Description of the sample is given in Table 1. 
Table 1. Subject demographics $(n=286)$

\begin{tabular}{lcc}
\hline Measure and items & Frequency & Percentage \\
\hline Gender & & \\
$\quad$ Female & 158 & 55.2 \\
$\quad$ Male & 128 & 44.8 \\
Study program & & \\
$\quad$ Information systems and technologies & 147 & 51.4 \\
$\quad$ Management and organization & 139 & 48.6 \\
Previous e-learning experience & & \\
$\quad$ Yes & 276 & 97.9 \\
$\quad$ No & 6 & 2.1 \\
Computer skills & & \\
$\quad$ Novice & 20 & 7.1 \\
Intermediate & 210 & 74.5 \\
$\quad$ Expert & 52 & 18.4 \\
Average e-learning hours per week & & \\
0-2 & 128 & 44.75 \\
3-5 & 125 & 43.71 \\
$>5$ & 33 & 11.54 \\
\hline
\end{tabular}

\subsection{Measures}

Based on previous research in this area (Liaw \& Chen, 2007; Selim, 2007; Sun et al., 2008; Y. Wang, 2003), we developed a questionnaire that consists of two groups of questions. The first group of question was intended to collect data for descriptive statistic, e.g., gender, computer skills, and previous e-learning experience. The second group of questions was intended to collect data about items that influence the attitude towards e-learning. These questions included adapted TAM subscales for measuring perceived usefulness and perceived ease of use (Davis et al., 1989), as well as items intended to collect answers regarding different types of contents included in e-learning materials. In addition, the second group of questions contained one question intended to examine a general attitude towards e-learning. Answers to these questions were offered in the form of the Likert scale of 7 levels ( $1=$ strongly disagree, $7=$ strongly agree).

\subsection{Procedure}

We adopted a survey approach. Participants were informed about the purpose and anonymous nature of the research orally. They participated voluntarily and were not remunerated. The questionnaire took approximately 10 minutes to complete.

For the statistical analysis of the obtained data we used the SPSS 20 software. To identify factors affecting attitudes towards e-learning, we conducted a Principal Component Analysis (PCA) of the 13 items related to the perceived usefulness, ease of use, and design of the e-learning system, using Direct Oblimin rotation. The number of factors to be extracted, was determined by an eigenvalue above 1.0 (the EGV1 criterion) and inspection of Scree plot (Cattell, 1966). Since EGV1 criterion and scree plot inspection may lead to factor over-retention (Patil, McPherson, \& Friesner, 2010), for determining a final number of factors we used the results of parallel analysis (Hayton, Allen, \& Scarpello, 2004). Additionally, we used a minimum individual item loading of .45 as a cutoff value, which Tabachnick \& Fidell (2013) consider as "fair".

To assess the impact of individual factors on attitude towards e-learning and to examine how well the combination of these factor can predict attitude towards e-learning, we used linear multiple regression (Tabachnick \& Fidell, 2013). Preliminary analyses were conducted to ensure no violation of the assumptions of normality, linearity, multicollinearity and homoscedasticity (Pallant, 2007). For all analyses confidence level was set to $95 \%$. 


\subsection{Results}

The significance of Bartlett's test of sphericity $(X 2(78)=1177.04, p<.001)$ and the size of the Kaiser-MeyerOlkin measure of sampling adequacy $(\mathrm{KMO}=.79)$ revealed that the variables had adequate common variance for factor analysis (Tabachnick \& Fidell, 2001).

The result of the PCA revealed three factors with the initial eigenvalues higher than $1(4.19,1.83$, and 1.41). Inspection of the scree plot also suggested retention of three factors. The results of a parallel analysis confirmed that the first three of the random data were smaller than the real data counterpart. These findings suggest that three factors should be extracted. In the three factor solution, the item "I like the author's photo included in e-learning materials" did not met the item loading criteria. We decided to exclude this item from further analysis.

The final, three-factor solution, contained 12 items, explaining $57.18 \%$ of the variance, and individual variance of factors are given in Table 2. The resulting factors were named as follows: (1) E-learning usefulness, (2) E-learning design, and (3) E-learning ease of use. The values of the Cronbach's alpha coefficients for the given factors are shown in Table 2.

Table 2. PCA - pattern matrix

\begin{tabular}{lrrr}
\hline \multirow{2}{*}{ Items } & \multicolumn{3}{c}{ Factors } \\
\cline { 2 - 4 } & $\mathbf{1}$ & \multicolumn{1}{c}{$\mathbf{2}$} & \multicolumn{1}{c}{$\mathbf{3}$} \\
\hline E-learning improves my thinking skills &. $\mathbf{8 6}$ & -.05 & -.05 \\
E-learning enhances my learning efficiency &. $\mathbf{8 0}$ & -.05 & .12 \\
E-learning encourages me to search for additional information on the & .78 & .13 & -.09 \\
topic of learning & .68 & .12 & .18 \\
E-learning is useful & .00 &. $\mathbf{8 1}$ & .08 \\
I like video instructions included in e-learning materials & .06 &. $\mathbf{8 0}$ & -.08 \\
I like the teacher's voice included in e-learning materials & -.11 & .77 & -.01 \\
I like animations included in e-learning materials & .20 & .50 & .08 \\
Hypertext in e-learning materials helps me in learning process & -.20 & .06 & .88 \\
It is easy for me to handle e-learning content & .00 & .08 & .71 \\
It is easy for me to find information in e-learning materials & .14 & -.06 & .70 \\
I find it easy to study through e-learning & .27 & -.08 & .65 \\
E-learning makes my learning process easier & 34.71 & 14.99 & 11.53 \\
\hline \% of variance explained & .82 & .73 & .75 \\
\hline Cronbach's alpha & &
\end{tabular}

The results of the multiple linear regression are presented in Figure 1. Preliminary analyses were conducted to ensure no violation of the assumptions of normality, linearity, multi collinearity and homoscedasticity was done. The model reached statistical significance $(F[3,282]=108.07, p<.001)$, and explains $53 \%$ variance of the attitude towards e-learning $(R$ square $=.53)$. E-learning usefulness had the greatest influence $(B e t a=.58, p<$ $.001)$, followed by the E-learning ease of use (Beta $=.22, p<.001$, and E-learning design (Beta $=.10, p<.05)$.

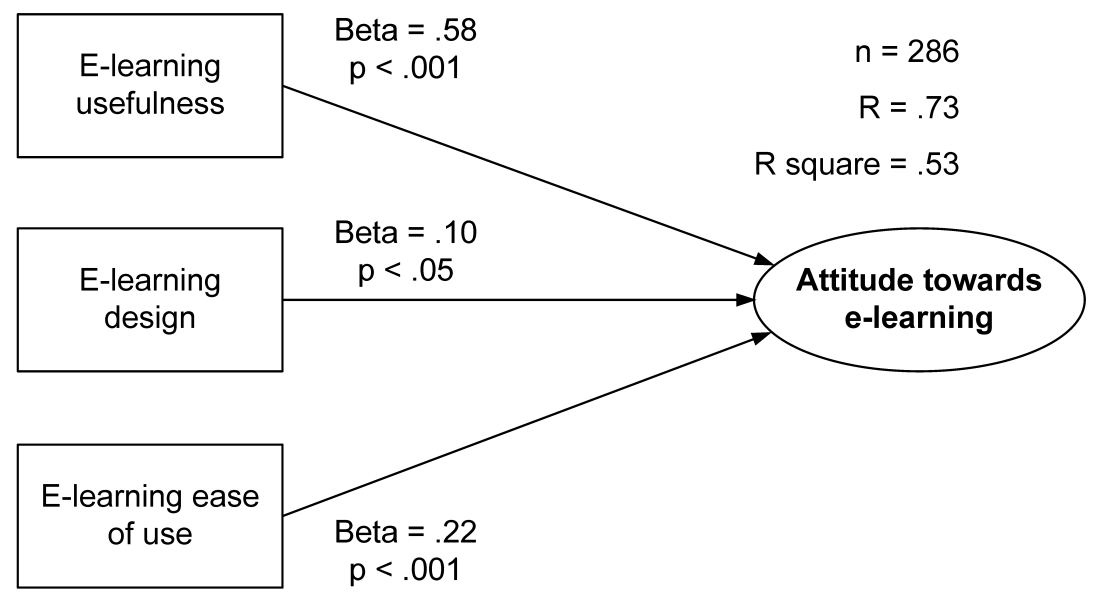

Figure 1: Results of multiple linear regression 


\section{Discussion}

In this study, we reported on the development of a measure that provides assessment of attitudes towards e-learning. We identified three factors that influence students' attitude towards e-learning. These factors are e-learning usefulness, ease of use, and design. Our findings suggest that with greater perceived usefulness, ease of use, and liking of the design of e-learning systems, students will have a more favorable attitude towards that system. Consequently, according to Davis's TAM theory (Davis et al., 1989), with a more favorable attitude, it is expected that the intention to use e-learning system among students will be greater.

Our findings are in line with previous work that confirmed the application of Davis's TAM theory in explaining acceptance of e-learning (Masrom \& Teknologi, 2007; Roca et al., 2006; Yi \& Hwang, 2003). We found that the ease of use and usefulness of e-learning significantly influenced attitudes towards e-learning, which corroborated previous studies (e.g., Teo \& Milutinovic, 2015; Teo, Milutinovic, \& Zhou, 2016) among the Serbian population. In addition, our results support other previous studies (e.g., Chung-Hoon \& Young-Gul, 2003; Masrom \& Teknologi, 2007; Park, 2009; Roca et al., 2006) that emphasized the potential of the TAM theory in acceptance of and intention to use e-learning.

In addition to the TAM theory constructs, the design of e-learning materials also had a significant influence. This is in accordance with previous research suggesting the importance of incorporating a variety of tactics to gain learner attention through the use of interesting graphics, animation, or any kind of event that introduces incongruity or conflict (Keller \& Suzuki, 2004). In addition, our findings confirm the importance of interactive experience throughout such design that will provide rich sensory experience and responses to learners actions (Damnjanovic et al., 2015; Jovic et al., 2012).

Although this study represents one of the few implementations of the TAM theory in e-learning in Serbia, there were some limitations to our study that need to be considered. The most significant limitation was a lack of repeated studies to test for invariance of the factor structure across different cohorts. Another limitation was the homogeneous nature of the sample. Replication of these results with a more heterogeneous sample in terms of age, socioeconomics, employment, and educational (i.e., non-student) background should further strengthen our understanding of predictors of attitudes towards e-learning. Finally, the study lacked confirmation of construct convergent and discriminant validity. This will be the subject of a future study, including structural equation modelling.

\section{Conclusion}

Regarding the evolving trends in e-learning, empirical results are required to determine the main factors that affect students' intention towards e-learning. We showed that three factors, namely, e-learning usefulness, ease of use, and content design, had the strongest influence on students' e-learning intention. Our results are in line with other research in this field, which emphasized the significance of usefulness and ease of use in accepting new technology. We want to emphasize the importance of content design for the use of e-learning, particularly due to our expectation that this factor will become more important over time.

The most important conclusion that arises from this study is that, in addition to usefulness and efficiency of e-learning systems, it is important to create the contents rich with audio and video clips, animations, and hyperlinks. A rich, multimedia design of e-learning materials will increase students' intention to use e-learning, together with generating more positive attitudes.

\section{REFERENCES}

[1] Arbaugh, J. B. (2002). Managing the on-line classroom : A study of technological and behavioral characteristics of Web- based MBA courses. The Journal of High Technology Management Research, 13, 203-223. DOI:10.1016/S1047-8310(02)00049-4

[2] Benkovic, S., \& Dobrota, M. (2012). Application of Teaching Methods and Techniques at Serbian Universities: Progress Over Time. Management, 63, 1820-222.

DOI:10.7595/management.fon.2012.0007

[3] Berman, N. B., \& Levine, D. A. (2008). Computer-Assisted Instruction in Clinical Education: a Roadmap to Increasing CAI Implementation Computer-Assisted Instruction in Clinical Education: a Roadmap to Increasing CAI Implementation. Advances in Health Sciences Education, 13, 373-383.

DOI:10.1007/s10459-006-9041-3 
[4] Bouhnik, D., \& Marcus, T. (2006). Interaction in Distance-Learning Courses, 57(3), 299-305. DOI:10.1002/asi

[5] Branscomb, L. M., \& Thomas, J. C. (1984). "Ease of use: A system design challenge." IBM Systems Journal, 23(3), 224-235. DOI:/10.1147/sj.233.0224

[6] Buzzetto-More, N. (2015). Student Attitudes Towards The Integration Of YouTube In Online, Hybrid, And Web-Assisted Courses: An Examination Of The Impact Of Course Modality On Perception. MERLOT Journal of Online Learning and Teaching, 11(1), 55-73.

[7] Cakir, R., \& Solak, E. (2014). Exploring the factors influencing e-learning of Turkish EFL learners through tam. Turkish Online Journal of Educational Technology, 13(3), 68-76.

[8] Capper, B. J. (2002). E-Learning Growth and Promise For the Developing World, 7-10.

[9] Cattell, R. B. (1966). The Scree Test For The Number Of Factors. Multivariate Behavioral Research, 1(2), 245-276. DOI:10.1207/s15327906mbr0102 10

[10] Chung-Hoon, P., \& Young-Gul, K. (2003). Idēntifying key factors affecting consumer purchase behavior in an online shopping context. International Journal of Retail \& Distribution Management, 31(1), 16-29. DOI:10.1108/09590550310457818

[11] Concannon, F., Flynn, A., \& Campbell, M. (2005). Benefits of E-Learning. British Journal of Educational Technology, 36(3), 501-512. DOI:10.1111/j.1467-8535.2005.00482.x

[12] Costley, J., \& Lange, C. H. (2017). Video lectures in e-learning: effects of viewership and media diversity on learning, satisfaction, engagement, interest, and future behavioral intention. Interactive Technology and Smart Education, 14(1), 1-19. DOI:10.1108/ITSE-08-2016-0025

[13] Damnjanovic, V., Jednak, S., \& Mijatovic, I. (2015). Factors affecting the effectiveness and use of Moodle: students' perception. Interactive Learning Environments, 23(4), 496-514. DOI:10.1080/10494820.2013.789062

[14] Davis, F. D., Bagozzi, R. P., \& Warshaw, P. R. (1989). User Acceptance of Computer Technology: A Comparison of Two Theoretical Models, 35(8). DOI:10.1287/mnsc.35.8.982

[15] Douglas, B. S., Gregg, F. C., \& Mangione, C. M. (2001). Self-study from Web-based and Printed Guideline Material. Annals of Internal Medicine, 134(6), 534-535. DOI:10.1109/ECTC.2012.6248958

[16] Hayton, J. C., Allen, D. G., \& Scarpello, V. (2004). Factor retention decisions in exploratory factor analysis: A tutorial on parallel analysis. Organizational Research Methods, 7, 191-205. DOI:10.1177/1094428104263675

[17] Hong, K.-S., K-W, L., \& D, H. (2003). Students' Satisfaction and Perceived Learning with a Web-based Course. Educational Technology and Society, 6(1), 1436-4522. DOI: 10.1016/S1096-7516(02)00105-7

[18] Horvat, A., Dobrota, M., Krsmanovic, M., \& Cudanov, M. (2015). Student perception of Moodle learning management system: a satisfaction and significance analysis. Interactive Learning Environments, 23(4), 515-527. DOI:10.1080/10494820.2013.788033

[19] Hung, I. C., Yang, X. J., Fang, W. C., Hwang, G. J., \& Chen, N. S. (2014). A context-aware video prompt approach to improving students' in-field reflection levels. Computers and Education, 70, 80-91. DOI:10.1016/j.compedu.2013.08.007

[20] Isik, C. (2008). E-Learning in Life Long Education. In College of Economic Studies Prague-CZ -E-learning Conference, 2008. (Vol. jun, pp. 1-6). DOI: 10.2139/ssrn.1409027

[21] Jiang, M., \& Ting, E. (1998). Course design, instruction, and students' online behaviors: A study of instructional variables and student perceptions of online learning. In Annual meeting of the American Educational Research Association, San Diego, CA.

[22] Jovic, M., Milutinovic, D., Kos, A., \& Tomazic, S. (2012). Product Presentation Strategy for Online Customers. Journal of Universal Computer Science, 18(10), 1323-1342. DOI: 10.3217/jucs-018-10-1323

[23] Keller, J. M., \& Suzuki, K. (2004). Learner motivation and E-learning design: a multinationally validated process, 29(3). DOI: 10.1080/1358t65042000283084

[24] Kim, K., \& Bonk, C. J. (2006). The Future of Online Teaching and Learning in Higher Education: The Survey Says ..., (4), 22-30.

[25] Kneebone, R. (2003). Simulation in surgical training: educational issues and practical implications, 37(3), 267-277. Medical Education, 37(3), 264-277. DOI: 10.1046/j.1365-2923.2003.01440.x

[26] Lee, M. (2010). Computers \& Education Explaining and predicting users' continuance intention toward e-learning: An extension of the expectation - confirmation model. Computers \& Education, 54(2), 506516. DOI: 10.1016/j.compedu.2009.09.002

[27] Liaw, S., \& Chen, G. (2007). An activity-theoretical approach to investigate learners' factors toward elearning systems, 23, 1906-1920. DOI: 10.1016/j.chb.2006.02.002 
[28] Luzon, J. M., \& Leton, E. (2015). Use of animated text to improve the learning of basic mathematics. Computers and Education, 88, 119-128. DOI: 10.1016/j.compedu.2015.04.016

[29] Masrom, M., \& Teknologi, U. (2007). Technology Acceptance Model and E-learning, (May), 1-10. DOI: $10.1002 / \mathrm{dir}$

[30] Motiwalla, L. F. (2007). Mobile learning : A framework and evaluation, 49, 581-596. DOI: 10.1016/j.compedu.2005.10.011

[31] Nahl, D. (1993). Communication dynamics of a live interactive television system for distance education. Journal of Education for Library and Information Science, 34(3), 200-217.

[32] Netemeyer, R., Ryn, M. Van, \& Ajzen, I. (1991). The theory of planned behavior. Organizational Behavior and Human Decision Processes, 50, 179-211. DOI: 10.1016/0749-5978(91)90020-T

[33] O'Connor, E., McDonald, F., \& Ruggiero, M. (2014). Scaffolding Complex Learning: Integrating 21st Century Thinking, Emerging Technologies, and Dynamic Design and Assessment to Expand Learning and Communication Opportunities. Journal of Educational Technology Systems, 43(2), 199-226. DOI: 10.2190/ET.43.2.g

[34] Oliver, R. L. (1986). A congitive model of the antecedents and consequences of satisfaction decisions. Journal of Marketing Research, 17, 460-469. DOI: 10.2307/3150499

[35] Pallant, J. (2007). SPSS Survival Manual. A step by step guide to data analysis using spss for windows.

[36] Park, S. Y. (2009). An Analysis of the Technology Acceptance Model in Understanding University Students' Behavioral Intention to Use e-Learning. Educational Technology \& Society, 12(3), 150-162. DOI: 10.1007/s00340-009-3513-0

[37] Park, S. Y., Nam, M.-W., \& Cha, S.-B. (2012). University students' behavioral intention to use mobile learning: Evaluating the technology acceptance model. British Journal of Educational Technology, 43(4), 592-605. DOI: 10.1111/j.1467-8535.2011.01229.x

[38] Patil, V. H., McPherson, M. Q., \& Friesner, D. (2010). The use of exploratory factor analysis in public health: A note on parallel analysis as a factor retention criterion. American Journal of Health Promotion, 24(3), 178-181. DOI: 10.4278/ajhp.08033131

[39] Roca, J. C., Chiu, C., \& Jose, F. (2006). Understanding e-learning continuance intention: An extension of the Technology Acceptance Model, 64, 683-696. DOI: 10.1016/j.ijhcs.2006.01.003

[40] Schwartz, R. A. (1995). The virtual university. American Society for Engineering Education Prism, 5(4), 22-26.

[41] Selim, H. M. (2007). Critical success factors for e-learning acceptance: Con W rmatory factor models ¿, 49, 396-413. DOI: 10.1016/j.compedu.2005.09.004

[42] Sharma, S., Dick, G., Chin, W., \& Land, L. (2007). Self-regulation and e-learning. In Fifteenth uropean Conference on Information System (pp. 383-394).

[43] Shee, D. Y., \& Wang, Y. (2008). Multi-criteria evaluation of the web-based e-learning system: A methodology based on learner satisfaction and its applications, 50, 894-905. DOI: 10.1016/j.compedu.2006.09.005

[44] Sun, P., Tsai, R. J., Finger, G., \& Chen, Y. (2008). What drives a successful e-Learning? An empirical investigation of the critical factors influencing learner satisfaction, 50, 1183-1202. DOI: 10.1016/j.compedu.2006.11.007

[45] Tabachnick, B. G., \& Fidell, L. S. (2013). Using multivariate statistics (6th ed.).

[46] Te'eni, D. (2004). Levels of abstraction in designs of human - computer interaction: The case of e-mail. DOI: 10.1016/j.chb.2004.02.028

[47] te Pas, E., Waard, M. W. de, Blok, B. S., Pouw, H., \& van Dijk, N. (2016). Didactic and technical considerations when developing e-learning and CME. Education and Information Technologies, 21(5), 991-1005. DOI: 10.1007/s10639-014-9364-2

[48] Teo, T., \& Milutinovic, V. (2015). Modelling the intention to use technology for teaching mathematics among pre-service teachers in Serbia. Australasian Journal of Educational Technology, 31 (4), 363-380. DOI: $10.14742 /$ ajet. 1668

[49] Teo, T., Milutinovic, V., \& Zhou, M. (2016). Modelling Serbian pre-service teachers â€ ${ }^{\mathrm{TM}}$ attitudes towards computer use: A SEM and MIMIC approach. Computers \& Education, 94, 77-88. DOI: 10.1016/j.compedu.2015.10.022

[50] Violante, M. G., \& Vezzetti, E. (2014). Implementing a new approach for the design of an e-learning platform in engineering education. Computer Applications in Engineering Education, 22(4), 708-727. DOI: $10.1002 /$ cae.21564

[51] Virvou, M., \& Katsionis, G. (1995). On the usability and likeability of virtual reality games for education: The case of VR-ENGAGE, 1-22. DOI: 10.1016/j.compedu.2006.04.004 
[52] Wang, J., \& Antonenko, P. D. (2017). Instructor presence in instructional video: Effects on visual attention, recall, and perceived learning. Computers in Human Behavior, 71, 79-89. DOI: 10.1016/j.chb.2017.01.049

[53] Wang, Y. (2003). Assessment of learner satisfaction with asynchronous electronic learning systems, 41, 75-86. DOI: 10.1016/S0378-7206(03)00028-4

[54] Yi, M. Y., \& Hwang, Y. (2003). Predicting the use of web-based information systems: self-efficacy, enjoyment, learning goal orientation , and the technology acceptance model, 59, 431-449.

DOI: 10.1016/S1071-5819(03)00114-9

(Received/Accepted)

(July 2016 / September 2017)

\section{University of Belgrade, Faculty of Organizational Sciences University of Belgrade, Faculty of Organizational Sciences
marijaj@fon.bg.ac.rs}

Marija Jovic is an assistant professor at the University of Belgrade, Faculty of Organizational Sciences. Her professional interests include digital marketing, e-commerce, and strategic marketing management.

About the Author

Milica Kostić Stanković

University of Belgrade, Faculty of Organizational Sciences milicak@fon.bg.ac.rs

Milica Kostic Stankovic is a full professor at the University of Belgrade, Faculty of

Organizational Sciences. Her major professional interests include marketing management, public relations, and business communication.

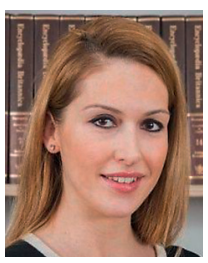

Ema Nešković

University of Belgrade, Faculty of Organizational Sciences ema.neskovic@fon.bg.ac.rs

Ema Neskovic is a teaching associate and a PhD student at the University of Belgrade, Faculty of Organizational Sciences. Her major professional interests include marketing management and public relations.
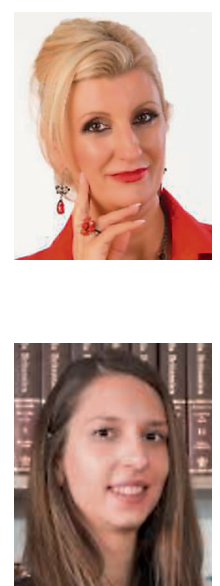